\title{
Investigating the in Vitro Antiproliferative and Apoptosis- Inducing Effects of Pyranochromene Derivatives
}

\author{
Mehdi Abaszadeh ${ }^{1}$ (D), Azade Ebrahimi ${ }^{2}$ (D), Salehe Sabouri 1,3,* (D) \\ 1 Pharmaceutics Research Center, Institute of Neuropharmacology, Kerman University of Medical Sciences, Kerman, Iran; \\ abaszadeh@kmu.ac.ir (M.A.); \\ 2 Student Research Committee, Faculty of Pharmacy, Kerman University of Medical Sciences, Kerman, Iran; \\ azyebrahimi@gmail.com (A.E.); \\ 3 Department of Pharmaceutical Biotechnology, Faculty of Pharmacy, Kerman University of Medical Sciences, Kerman, \\ Iran; ssabouri@kmu.ac.ir (S.S.); \\ * Correspondence: ssabouri@kmu.ac.ir;
}

Received: 17.10.2020; Revised: 11.11.2020; Accepted: 13.11.2020; Published: 15.11.2020

\begin{abstract}
Cancer is one of the important health problems, and researchers continue their efforts to discover new anti-cancer agents. Coumarins (chromene-2-ones), a group of natural metabolites, have shown different biological activities based on their substitutions. In this study, 15 compounds of 1,5dihydropyrano[2,3-c]chromene were synthesized by three-component reaction and investigated for the antiproliferative activity on the breast (MCF-7), colorectal (SW48 and HT-29), lung (A549), and brain (U-87 MG) cancer cell lines as well as two normal cell lines (3T3 and HUVEC). The apoptosis/necrosisinducing effect of the selected compounds was determined on the MCF-7 cell line by flow cytometry. The results showed that the compounds bearing a moiety on their phenyl ring's para position had potent cytotoxic effects on the tested cell lines. These compounds induced apoptosis in MCF-7 cells. The compounds were also toxic for 3T3 and HUVECs and did not display a high selectivity for tumor cells. Our results revealed that the compounds having a moiety at the para position of their phenyl ring might be suitable lead compounds for the synthesis of potent anti-cancer agents.
\end{abstract}

Keywords: anti-cancer activity; apoptosis; antitumor; pyranochromene; coumarin.

(C) 2020 by the authors. This article is an open-access article distributed under the terms and conditions of the Creative Commons Attribution (CC BY) license (https://creativecommons.org/licenses/by/4.0/).

\section{Introduction}

Cancer is considered the most challenging problem, and the second leading cause of death worldwide [1]. Aging and population growth have increased the incidence and mortality of cancers [2]. Cancer incidence is complicated and under the effect of several factors; however, the extrinsic factors have more influence, causing increased cancer development in young adults [3]. One-third of cancer incidence and mortality is related to lung, breast, and colorectal cancers worldwide. Lung and colorectal cancers are the first and second mortal cancers for both sexes. Among females, however, breast cancer is the leading cause of cancer death [2]. From 2012 to 2016, the death rate for brain and other nervous system tumors has increased, and these types of cancers are the leading cause of cancer death among young adults [1]. Gliomas are the second most common brain tumors in adults, and glioblastomas are the most aggressive and invasive type $[4,5]$.

Radiotherapy and surgery are used to treat localized tumors and chemotherapy and immunotherapy for hematologic or metastatic malignancies. However, the best method of cancer treatment is still chemotherapy. Nevertheless, drug resistance is a problem in cancer 
therapy, which leads to the failure of the treatment $[6,7]$. Therefore, researchers continue their efforts to discover new antitumor agents. Additionally, angiogenesis, a neo-vessel growth pathway, has a role in tumorigenesis; thus, angioprevention can also be used to prevent and treat cancers, and scientists are looking for anti-angiogenesis compounds [8,9].

Coumarins are the most diverse and abundant family of secondary metabolites exhibiting a wide range of pharmacological activities. These compounds are well known for their anticoagulant effects. Additionally, coumarins have shown antioxidant, antiviral, antiparasitic, antifungal, antibacterial, antitumor, anti-inflammatory, and anti-Alzheimer effects based on the substitution pattern [10-16]. There are extensive reports of the antitumor activity of synthetic and natural coumarin derivatives in many tumor cells, including those of colorectal, gastric, breast, and lung cancers [12]. Coumarins exert their anti-cancer effects by inhibiting angiogenesis, aromatase, telomerase, protein kinase activity, arresting cell cycle, producing oxidative stress via generating free radical species inducing apoptosis [17-20].

The present study aimed to investigate the in vitro antiproliferative and anti-apoptotic effects of 15 derivatives of synthesized 3-hydroxy coumarin.

\section{Materials and Methods}

\subsection{Synthesis of the compounds.}

A series of 1,5-dihydropyrano[2,3-c]chromene derivatives (4a-o) were synthesized by the three-component reaction of 3-hydroxycoumarin (1), malononitrile (2), and aromatic aldehydes (3a-o) in the presence of piperidine as a base in $\mathrm{EtOH}$ and under reflux conditions. This method was based on our previous works on environmentally friendly multi-component reactions [21-23]. The compounds were prepared as previously reported [24-29].

\subsection{Cell culture.}

U-87 MG (human glioblastoma), A549 (human lung), MCF-7 (human breast), SW48 and HT-29 (human colorectal) cancer cell lines, HUVEC (human umbilical vein endothelial cells), and 3T3 (mouse embryonic fibroblast) normal cell lines were purchased from the Iranian Biological Resource Center (IBRC, Tehran, Iran) and cultured in Dulbecco's modified Eagle's medium (DMEM, Gibco) supplemented with 10\% heat-inactivated fetal bovine serum (FBS, Gibco), and antibiotics (100 U/ml penicillin and $100 \mu \mathrm{g} / \mathrm{ml}$ streptomycin, Biosera). The cells were incubated at $37{ }^{\circ} \mathrm{C}, 5 \% \mathrm{CO}_{2}$, and $95 \%$ relative humidity up to at least $80 \%$ confluent.

\subsection{Cytotoxicity assay by MTT.}

To evaluate the antiproliferative effects of the compounds, MTT assay was performed. The cells were trypsinized, $1 \times 10^{4}$ cells were cultured in each well of a 96-well microplate, and the microplates were incubated in the above-mentioned conditions for $24 \mathrm{~h}$. The next day, different concentrations (from 0.1 to $500 \mu \mathrm{g} / \mathrm{ml}$ ) of the compounds were added, and the cells were incubated for a further $24 \mathrm{~h}$. Doxorubicin (the most potent anti-cancer drug) was used as the reference. At least 3 wells of the microplate were used for each concentration, and the experiment was repeated 3 times. Finally, MTT solution $(5 \mathrm{mg} / \mathrm{ml}$, Melford, England) was added to the wells, and the microplates were incubated for $3 \mathrm{~h}$ protected from light. Formazan crystals were solubilized in $100 \mu \mathrm{l}$ DMSO, and the absorbance was measured at $570 \mathrm{~nm}$ in a 
multiplate reader. The $\mathrm{IC}_{50}$ values were calculated using a nonlinear curve of dose-response in GraphPad ${ }^{\circledR}$ Prism version 5 from the percent of viable cells vs. logarithm of concentrations.

The selectivity index (SI) was calculated by dividing the compound's IC50 value on $3 \mathrm{~T} 3$ by the $\mathrm{IC}_{50}$ value on the cancer cell line [30].

\subsection{Cytotoxicity assay by trypan blue dye exclusion.}

MCF-7 cells were cultured at 6-well plates $\left(5 \times 10^{5}\right.$ cells/well $)$ and incubated for $24 \mathrm{~h}$. Different concentrations of the compounds $(0.1,1,10,50$, and $100 \mu \mathrm{g} / \mathrm{ml})$ were added to each well and incubated for $24 \mathrm{~h}$. The cells were trypsinized and combined with trypan blue. Then the numbers of the dead and the live cells were counted on a Hemocytometer.

\subsection{Apoptosis assay by flow cytometry.}

MCF-7 cells were treated with $50 \mu \mathrm{g} / \mathrm{ml}$ solutions of one of the compounds $4 \mathrm{c}, 4 \mathrm{e}, 4 \mathrm{~g}$, $4 \mathrm{~h}, 4 \mathrm{j}$, or 41 , or $250 \mu \mathrm{g} / \mathrm{ml}$ of $4 \mathrm{n}$ for $24 \mathrm{~h}$. Detection of apoptosis in cells was carried out by flow cytometry the next day using Annexin-V-FITC/ PI (propidium iodide) Apoptosis Kit (MabTag, Germany) based on the manufacturer's protocol. Briefly, the cells were trypsinized and washed twice in ice-cold PBS. The cells were then suspended in the binding buffer to a concentration of $1 \times 10^{6}$ cells $/ \mathrm{ml}$, later stained with PE annexin-V and PI, and incubated in the dark. Cell analysis was done with the flow cytometer $\left(\mathrm{CyFlow}^{\circledR}\right.$, Sysmex Partec GmbH, Germany).

\section{Results and Discussion}

\subsection{Chemistry.}

We have synthesized a series of 1,5-dihydropyrano[2,3-c]chromene derivatives. The synthesized compounds $4 \mathrm{a}$ to $4 \mathrm{o}$ were identified by comparing their melting points and FTIR spectra with those of authentic samples. The synthesis process and the structure of the compounds are shown in Scheme 1.

\subsection{Cytotoxicity assay by MTT.}

To evaluate the cytotoxic activity of the synthesized compounds, several cell lines were incubated with different concentrations of the compounds, and their viabilities were determined after $24 \mathrm{~h}$. The IC 50 values calculated from MTT assay results showed that compounds $4 \mathrm{c}, 4 \mathrm{e}$, $4 \mathrm{~g}, 4 \mathrm{~h}, 4 \mathrm{j}$, and 41 have toxic effects on some of the tested cell lines (Table 1). The compounds were significantly cytotoxic for the MCF-7 cell line. Among all the compounds, $4 \mathrm{~h}$ showed high toxicity on all the tested cell lines, and unlike other compounds, it was toxic for the A549 cells. Most of the compounds were not toxic for the U-87 cell line except compounds $4 \mathrm{~g}$ and 4h. It should be noted that most of these compounds were also toxic for the regular cell lines (3T3 and HUVEC). The cytotoxicity of some compounds such as $4 \mathrm{c}$ and $4 \mathrm{~g}$ was more on the 3T3 than on the MCF-7 cells, and compound 4o was toxic for the 3T3 cells despite the lack of toxicity for the cancer cell lines. However, the SI (selective index) values of compounds $4 \mathrm{e}, 4 \mathrm{j}$, and 41 for MCF-7 were 3.62, 5.17, and 2.48, respectively. Also, compounds 4c, 4e, 4g, 4h, 4j, and 41 were toxic for the HUVECs.

Six out of 15 compounds tested in this study were effective on growth inhibition of the cell lines. All the useful compounds had a moiety at the para position of their phenyl rings. 
Compounds $4 \mathrm{~g}$ and $4 \mathrm{~h}$ with a $\mathrm{Cl}$ atom at the para position were potent antiproliferative agents. Although the additional chlorine group at the ortho site of the phenyl ring of compound $4 \mathrm{~h}$ increased its toxicity on A549 and U-87 cells dramatically, it did not have such an effect on MCF-7 cell line. In fact, $4 \mathrm{~h}$ was the only compound effective on A549 cell line. In addition to $4 \mathrm{~h}, 4 \mathrm{~g}$ was also effective on the U-87 cell line with a higher $\mathrm{IC}_{50}$. Unlike these two chlorinated compounds, compound $4 \mathrm{f}$ bearing one $\mathrm{Cl}$ atom at an ortho position was not cytotoxic to any cell lines. It seems that the para position must be substituted in order for the ortho position to increase its cytotoxic effects. In other words, substitution at the ortho position alone is not sufficient for cytotoxicity of the compounds. This is true for other moieties $\left(\mathrm{Br}, \mathrm{CH}_{3}, \mathrm{OCH}_{3}\right)$, too, in which ortho position is not a suitable substitution.

In the same way, meta-position did not lead to the production of cytotoxic compounds as seen in compounds $4 \mathrm{k}$ and $4 \mathrm{n}$ with $\mathrm{F}$ and $\mathrm{NO}_{2}$ groups at meta position, respectively. Simultaneously, their equivalents having these groups at para position (4l and 40) were cytotoxic. It can be concluded that a moiety at the para position is necessary for toxic effects. However, the $\mathrm{NO}_{2}$ group was not as effective as halogens, methoxy, and methyl groups. This may be related to its high electron-withdrawing effect.

Furthermore, the TPSA (topological polar surface area) of the compounds with $\mathrm{NO}_{2}$ functional group is higher. It is seen that the higher the TPSA is, the less the in vitro toxicity will be [31]. Basanagouda et al. tested iodinated-4-aryloxymethyl-coumarins on breast and lung cancer cell lines and concluded that the halogenated compounds exhibited potent activity [32]. Our previous work on dihydropyrano[3,2-b]chromene derivatives, compounds having halogens, $\mathrm{CH}_{3}$, and $\mathrm{OCH}_{3}$ substitutions showed cytotoxic activity against cancer cell lines [33]. Similarly, there was no remarkable difference between halogens, methoxy, and methyl substitutions in this work.

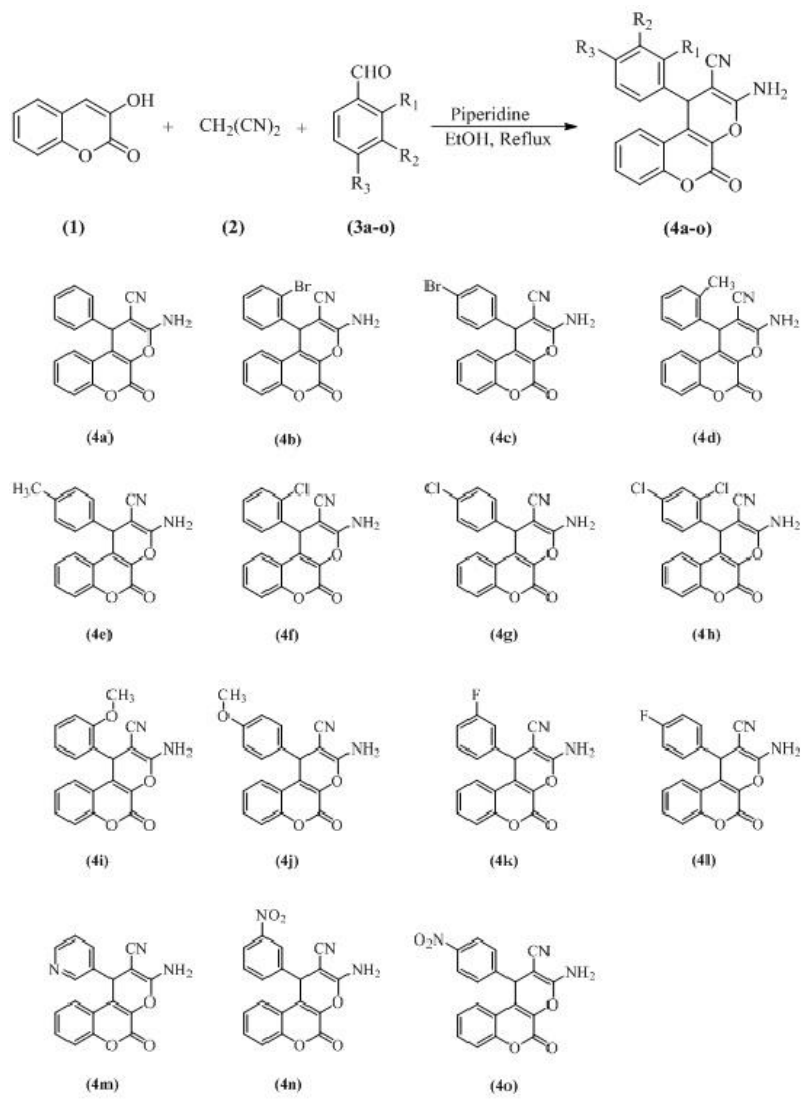

Scheme 1. Synthesis of 1,5-dihydropyrano[2,3-c]chromene derivatives. (1) 3-hydroxycoumarin, (2) malononitrile, (3a-o) aromatic aldehydes, (4a-o) the synthesized compounds. 
Table 1. $\mathrm{IC}_{50}(\mu \mathrm{g} / \mathrm{ml})$ values of the compounds (mean \pm S.E.M). Values are reported from three independent experiments.

\begin{tabular}{l|l|l|l|l|l|l|l} 
Code & MCF-7 & SW48 & HT-29 & A549 & U87 & HUVEC & 3T3 \\
\hline $\mathbf{4 a}$ & $>500$ & $>500$ & $>500$ & $>500$ & $>500$ & $>500$ & $>500$ \\
\hline $\mathbf{4 b}$ & $>500$ & $>500$ & $>500$ & $>500$ & $>500$ & $304.25 \pm 14.15$ & $>500$ \\
\hline $\mathbf{4 c}$ & $21.34 \pm 2.52$ & $47.43 \pm 5.11$ & $70.00 \pm 7.21$ & $293.6 \pm 19.30$ & $399.6 \pm 26.57$ & $13.17 \pm 0.35$ & $11.85 \pm 0.29$ \\
\hline $\mathbf{4 d}$ & $>500$ & $>500$ & $>500$ & $>500$ & $>500$ & $>500$ & $>500$ \\
\hline $\mathbf{4 e}$ & $39.04 \pm 4.82$ & $283.5 \pm 10.89$ & $146.9 \pm 9.32$ & $300.5 \pm 14.98$ & $502 \pm 17.38$ & $35.69 \pm 3.25$ & $141.66 \pm 16.08$ \\
\hline $\mathbf{4 f}$ & $>500$ & $>500$ & $>500$ & $>500$ & $>500$ & $>500$ & $>500$ \\
\hline $\mathbf{4 g}$ & $24.47 \pm 1.69$ & $44.94 \pm 5.65$ & $44.17 \pm 10.40$ & $230.8 \pm 15.52$ & $74.03 \pm 15.08$ & $10.48 \pm 0.69$ & $9.91 \pm 0.81$ \\
\hline $\mathbf{4 h}$ & $15.25 \pm 1.05$ & $19.69 \pm 4.74$ & $21.33 \pm 6.81$ & $55.38 \pm 8.83$ & $18.72 \pm 5.22$ & $16.15 \pm 1.29$ & $17.28 \pm 2.09$ \\
\hline $\mathbf{4 i}$ & $>500$ & $>500$ & $>500$ & $>500$ & $>500$ & $>500$ & $>500$ \\
\hline $\mathbf{4 j}$ & $37.47 \pm 1.42$ & $204.7 \pm 7.29$ & $>500$ & $>500$ & $250.1 \pm 16.88$ & $12.49 \pm 0.093$ & $193.86 \pm 11.87$ \\
\hline $\mathbf{4 k}$ & $>500$ & $>500$ & $>500$ & $>500$ & $>500$ & $>500$ & $>500$ \\
\hline $\mathbf{4 l}$ & $38.16 \pm 3.97$ & $93.50 \pm 6.27$ & $87.05 \pm 8.67$ & $206.3 \pm 8.50$ & $305.0 \pm 15.72$ & $29.08 \pm 0.1$ & $94.63 \pm 7.74$ \\
\hline $\mathbf{4 m}$ & $>500$ & $>500$ & $>500$ & $>500$ & $>500$ & $>500$ & $>500$ \\
\hline $\mathbf{4 n}$ & $>500$ & $>500$ & $>500$ & $>500$ & $>500$ & $>500$ & $>500$ \\
\hline $\mathbf{4 o}$ & $339.43 \pm 55.29$ & $>500$ & $367.6 \pm 30.37$ & $383.5 \pm 12.89$ & $>500$ & $124.13 \pm 3.16$ & $79.41 \pm 5.60$ \\
\hline $\mathbf{D o x}$ & $5.13 \pm 0.31$ & $5.08 \pm 0.27$ & $4.98 \pm 0.23$ & $6.32 \pm 0.19$ & $7.64 \pm 0.34$ & $7.36 \pm 0.54$ & $6.25 \pm 0.21$
\end{tabular}

Dox: doxorubicin

\subsection{Cytotoxicity assay by trypan blue dye exclusion.}

The trypan blue dye exclusion test (Figure 1) confirmed the MTT assay results in that $4 \mathrm{~h}$ lowered the percent of viable cells dramatically at the concentration of $50 \mu \mathrm{g} / \mathrm{ml}$. In other words, $4 \mathrm{~h}$ followed by $4 \mathrm{c}$ and $4 \mathrm{l}$ were the most toxic agents that disturbed the cell membrane's integrity. Surprisingly, compound 4o, which did not show cytotoxicity on the MCF-7 in the MTT assay, brought the viable cells below $50 \%$ at $100 \mu \mathrm{g} / \mathrm{ml}$ concentration.

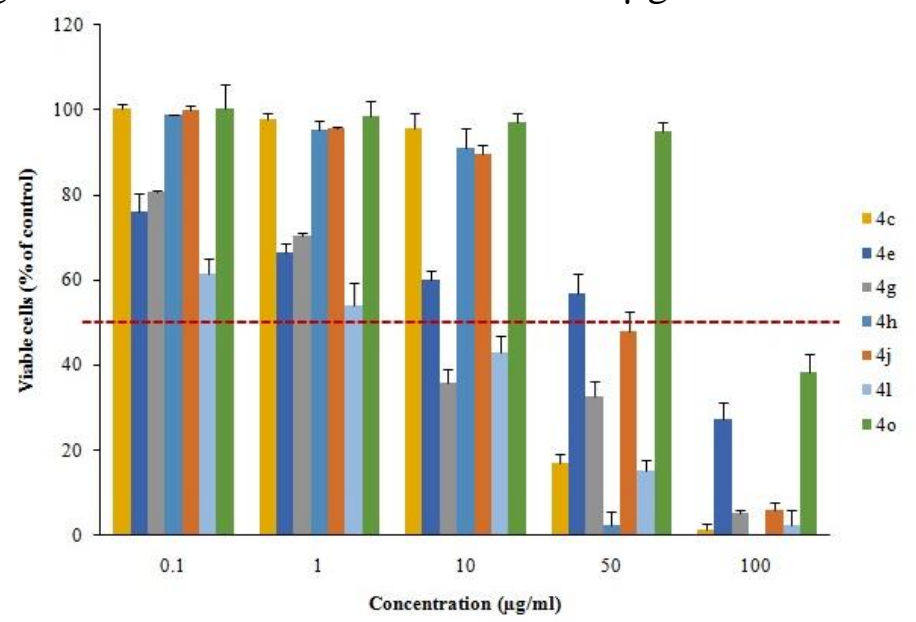

Figure 1. Cytotoxicity assay of the compounds by Trypan blue dye exclusion method. MCF-7 cells were treated with compounds for $24 \mathrm{~h}$. The data represent the mean $\pm \mathrm{SD}$.

\subsection{Apoptosis assay by flow cytometry.}

To investigate the compounds' apoptotic activity, MCF-7 cells treated with the compounds for $24 \mathrm{~h}$ were stained with a combination of Annexin V-FITC and PI and analyzed in a flow cytometer. The results of this part of the experiment are shown in Figure 2. It confirmed that all tested compounds induced apoptosis in MCF-7 cells except 4o, which induced necrosis at high concentration.

There are several reports of apoptosis-inducing activity of coumarin derivatives and hybrids. The 6-brominated coumarin hydrazide-hydrazone derivatives showed potent antiproliferative activity and induced apoptosis in a pancreatic cancer cell line [17]. Oprenylated coumarin derivatives showed antiproliferative effects on HeLa cells and induced 
apoptosis after $48 \mathrm{~h}$ treatment; however, these compounds did not inhibit HDF normal cells [34]. Some thiazolylpyrazolyl coumarin derivatives also were toxic for the MCF-7 cell line and induced apoptosis and cell cycle arrest in these cells [35].
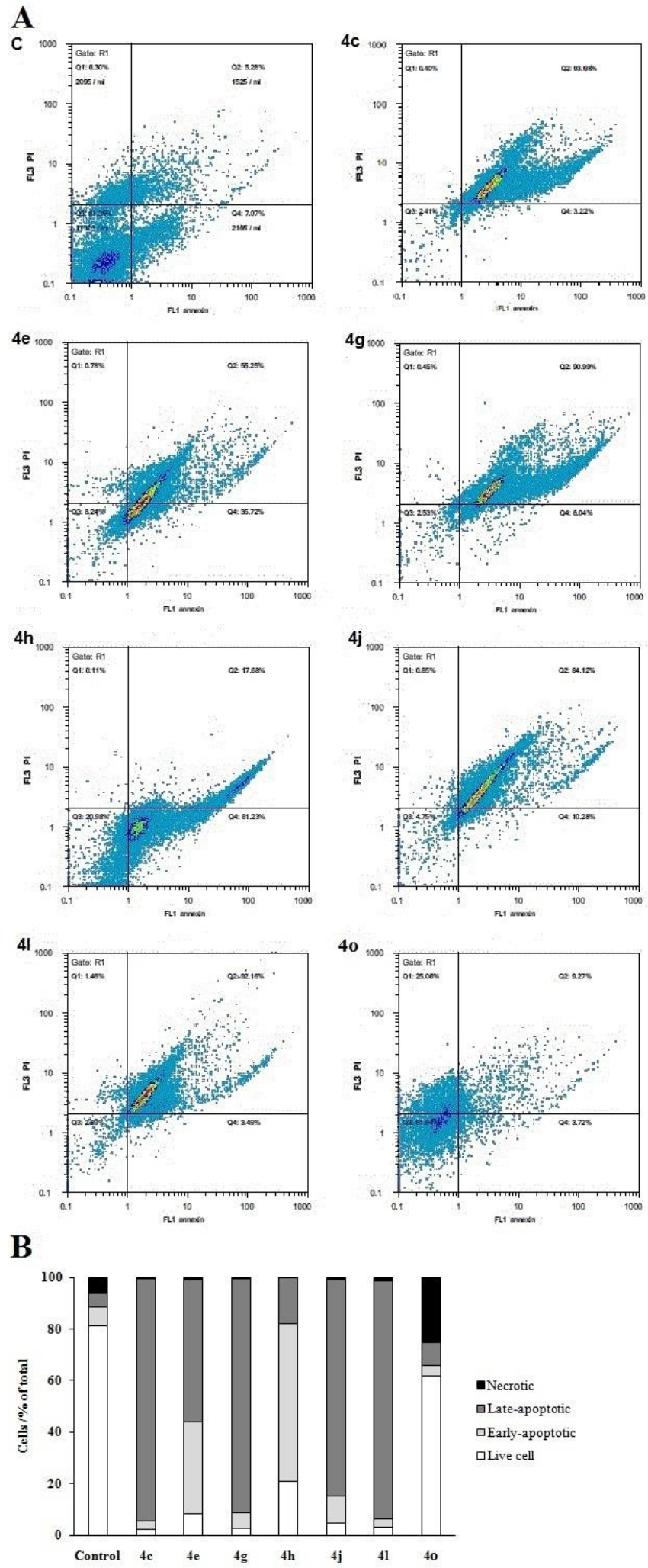

Figure 2. The apoptosis assay by flow cytometry. MCF-7 cells were treated with the compounds for $24 \mathrm{~h}$. A) Dot plots showing apoptosis ratios using propidium iodide (PI) and FITC-annexin V. The Q1 quadrant represents necrotic cells (PI-positive and annexin negative), the Q2 represents late apoptotic cells (PI and annexin positive), the Q3 represents viable cells (PI and annexin negative). The Q4 represents early apoptotic cells (PI negative and annexin positive). C stands for control. B) Bar graph showing the percentage of cells in different states. Note the percentage of apoptotic cells (dark and bright grey). 


\section{Conclusions}

Based on our results, 1,5-dihydropyrano[2,3-c]chromene derivatives can be considered suitable lead compounds for the synthesis of anti-cancer agents. A moiety on the para position of the phenyl ring showed in vitro toxic activity against cancer cell lines by introducing apoptosis. Therefore, these compounds can be considered as motivating anti-cancer agents for further study. Although HUVEC is a standard cell line, it is mostly used for evaluating the angiogenesis, preventing the potential of chemicals, so further research can be performed to investigate the anti-angiogenesis effect of these compounds.

\section{Funding}

This research was funded by Kerman University of Medical Sciences, grant number 95000015 and 97001020.

\section{Acknowledgments}

This research has no acknowledgment.

\section{Conflicts of Interest}

The authors declare no conflict of interest.

\section{References}

1. Siegel, R.L.; Miller, K.D.; Jemal, A. Cancer statistics, 2019. CA Cancer J. Clin. 2019, 69, 7-34, https://doi.org/10.3322/caac.21551.

2. Bray, F.; Ferlay, J.; Soerjomataram, I.; Siegel, R.L.; Torre, L.A.; Jemal, A. Global cancer statistics 2018: GLOBOCAN estimates of incidence and mortality worldwide for 36 cancers in 185 countries. CA Cancer J. Clin. 2018, 68, 394-424.

3. Yang, W.; Kehm, R.D.; Terry, M.B. Survival model methods for analyses of cancer incidence trends in young adults. Statistics in Medicine 2020, 39, 1011-1024, https://doi.org/10.1002/sim.8458.

4. McNeill, K.A. Epidemiology of brain tumors. Neurol. Clin. 2016, 34, 981-998, https://doi.org/10.1016/j.ncl.2016.06.014.

5. Ostrom, Q.T.; Adel Fahmideh, M.; Cote, D.J.; Muskens, I.S.; Schraw, J.M.; Scheurer, M.E.; Bondy, M.L. Risk factors for childhood and adult primary brain tumors. Neuro-Oncol. 2019, 21, 1357-1375, https://doi.org/10.1093/neuonc/noz123.

6. Mansoori, B.; Mohammadi, A.; Davudian, S.; Shirjang, S.; Baradaran, B. The different mechanisms of cancer drug resistance: a brief review. Adv. Pharm. Bull. 2017, 7, 339-348, https://doi.org/10.15171/apb.2017.041.

7. Nikolaou, M.; Pavlopoulou, A.; Georgakilas, A.G.; Kyrodimos, E. The challenge of drug resistance in cancer treatment: a current overview. Clin. Exp. Metastasis 2018, 35, 309-318, https://doi.org/10.1007/s10585-0189903-0.

8. Quintero-Fabián, S.; Arreola, R.; Becerril-Villanueva, E.; Torres-Romero, J.C.; Arana-Argáez, V.E.; LaraRiegos, J.; Ramírez-Camach, M.A.; Alvarez-Sanchez, M.E. Role of matrix metalloproteinases in angiogenesis and cancer. Front. Oncol. 2019, 9, https://doi.org/10.3389/fonc.2019.01370.

9. Wang, Z.; Dabrosin, C.; Yin, X.; Fuster, M.M.; Arreola, A.; Rathmell, W.K.; Generali, D.; Nagaraju, G.P.; El-Rayes, B.; Ribatti, D.; Chen, Y.C. Broad targeting of angiogenesis for cancer prevention and therapy. Semin. Cancer Biol. 2015, 35, S224-S43, https://doi.org/10.1016/j.semcancer.2015.01.001.

10. Zhang, L.; Xu, Z. Coumarin-containing hybrids and their anti-cancer activities. Eur. J. Med. Chem. 2019, 181, https://doi.org/10.1016/j.ejmech.2019.111587.

11. Venugopala, K.N.; Rashmi, V.; Odhav, B. Review on natural coumarin lead compounds for their pharmacological activity. BioMed Res. Int. 2013, 2013, 1-14, https://doi.org/10.1155/2013/963248.

12. Peng, X.M.; LV Damu, G.; Zhou, H. Current developments of coumarin compounds in medicinal chemistry. Curr. Pharm. Des. 2013, 19, 3884-3930, https://doi.org/10.2174/1381612811319210013.

13. Menezes, J.C.; Diederich, M. Translational role of natural coumarins and their derivatives as anti-cancer agents. Future Med. Chem. 2019, 11, 1057-1082, https://doi.org/10.4155/fmc-2018-0375. 
14. Küpeli Akkol, E.; Genç, Y.; Karpuz, B.; Sobarzo-Sánchez, E.; Capasso, R. Coumarins and coumarin-related compounds in pharmacotherapy of cancer. Cancers 2020, 12, https://doi.org/10.3390/cancers12071959.

15. Gouda, M.A.; Salem, M.A.; Helal, M.H. A review on synthesis and pharmacological activity of coumarins and their analogs. Curr. Bioact. Compd. 2020, 16, 818-836, https://doi.org/10.2174/1573407215666190405154406.

16. Alshibl, H.M.; Al-Abdullah, E.S.; Alkahtani, H.M. Coumarin: a promising scaffold for design and development of bioactive agents. Curr. Bioact. Compd. 2020, 16, 837-852, https://doi.org/10.2174/1573407215666190524101510.

17. Nasr, T.; Bondock, S.; Youns, M. Anticancer activity of new coumarin substituted hydrazide-hydrazone derivatives. Eur. J. Med. Chem. 2014, 76, 539-548, https://doi.org/10.1016/j.ejmech.2014.02.026.

18. Thakur, A.; Singla, R.; Jaitak, V. Coumarins as anti-cancer agents: a review on synthetic strategies, mechanism of action and SAR studies. Eur. J. Med. Chem. 2015, 101, 476-495, https://doi.org/10.1016/j.ejmech.2015.07.010.

19. Önder, Alev. Anti-cancer activity of natural coumarins for biological targets. In: Studies in Natural Products Chemistry. Rahman A.U. Ed.; Elsevier, Volume 64, 2020; pp. 85-109, https://doi.org/10.1016/B978-0-12817903-1.00003-6.

20. Ahmed, E.Y.; Latif, N.A.A.; El-Mansy, M.F.; Elserwy, W.S.; Abdelhafez, O.M. VEGFR-2 inhibiting effect and molecular modeling of newly synthesized coumarin derivatives as anti-breast cancer agents. Bioorg. Med. Chem. 2020, 28, https://doi.org/10.1016/j.bmc.2020.115328.

21. Abaszadeh, M.; Seifi, M.; Asadipour, A. Nanosized MgO as a heterogeneous base catalysts, catalyses multicomponent reaction of cyclic enaminoketones, malononitrile, and aromatic aldehydes. Synth. React. Inorg. Met-Org. Nano-Met. Chem. 2016, 46, 512-517, https://doi.org/10.1080/15533174.2014.988812.

22. Abaszadeh, M.; Seifi, M.; Ebrahimipour, S.Y. Two ligand oxidio-vanadium (IV) complexes as novel efficient catalysts in multi-component reactions for synthesis of tetrahydrobenzopyran derivatives. Bull. Chem. Soc. Ethiop. 2016, 30, 253-262, https://doi.org/10.4314/bcse.v30i2.9.

23. Abaszadeh, M.; Seifi, M. Ultrasound-assisted 1, 3-dipolar cycloaddition and cyclopropanation reactions for the synthesis of bis-indolizine and bis-cyclopropane derivatives. Org. Biomol. Chem. 2014, 12, 7859-7863, https://doi.org/10.1039/C4OB01305K.

24. Patra, A.; Mahapatra, T. Synthesis of dihydropyrano [c] chromenes from hydroxycoumarins using Aliquat ${ }^{\circledR}$ 336 catalyzed condensation in aqueous medium. J. Indian Chem. Soc. 2012, 89, 925-933, https://doi.org/10.1002/chin.201313122.

25. Paul, S.; Bhattacharyya, P.; Das, A.R. One-pot synthesis of dihydropyrano [2, 3-c] chromenes via a three component coupling of aromatic aldehydes, malononitrile, and 3-hydroxycoumarin catalyzed by nanostructured $\mathrm{ZnO}$ in water: a green protocol. Tetrahedron Lett. 2011, 52, 4636-4641, https://doi.org/10.1016/j.tetlet.2011.06.101.

26. Das, P.; Dutta, A.; Bhaumik, A.; Mukhopadhyay, C. Heterogeneous ditopic $\mathrm{ZnFe}_{2} \mathrm{O}_{4}$ catalyzed synthesis of 4 H-pyrans: further conversion to 1, 4-DHPs and report of functional group interconversion from amide to ester. Green Chem. 2014, 16, 1426-1435, https://doi.org/10.1039/C3GC42095G.

27. Paul, S.; Ghosh, S.; Bhattacharyya, P.; Das, A.R. Synthesis of a $\mathrm{SO}_{3} \mathrm{H}$-bearing carbonaceous solid catalyst, PEG-SAC: application for the easy access to a diversified library of pyran derivatives. $R S C A d v . \mathbf{2 0 1 3}, 3$, 14254-14262. https://doi.org/10.1039/C3RA42352B.

28. Mohammadzadeh, I.; Asadipour, A.; Pardakhty, A.; Abaszadeh, M. New crown ether-based ionic liquids as a green and versatile organocatalyst for three-component synthesis of 1, 5-dihydropyrano [2, 3-c] chromene derivatives. Lett. Org. Chem. 2020, 17, 240-245, https://doi.org/10.2174/1570178616666190620124947.

29. Abaszadeh, M.; Sheibani, H.; Mola, A. Theoretical and experimental investigations into the structural, electronic, and molecular properties of 1,5-dihydropyrano[2,3-c]chromene derivatives. Biointerface Res. Appl. Chem. 2020, 10, 5586-5591, https://doi.org/10.33263/BRIAC103.586591.

30. Peña-Morán, O.A.; Villarreal, M.L.; Álvarez-Berber, L.; Meneses-Acosta, A.; Rodríguez-López, V. Cytotoxicity, post-treatment recovery, and selectivity analysis of naturally occurring podophyllotoxins from Bursera fagaroides var. fagaroides on breast cancer cell lines. Molecules 2016, 21, https://doi.org/10.3390/molecules21081013.

31. Lu, S.; Jessen, B.; Strock, C.; Will, Y. The contribution of physicochemical properties to multiple in vitro cytotoxicity endpoints. Toxicol. In Vitro 2012, 26, 613-620, https://doi.org/10.1016/j.tiv.2012.01.025.

32. Basanagouda, M.; Jambagi, V.B.; Barigidad, N.N.; Laxmeshwar, S.S.; Devaru, V. Synthesis, structureactivity relationship of iodinated-4-aryloxymethyl-coumarins as potential anti-cancer and anti-mycobacterial agents. Eur. J. Med. Chem. 2014, 74, 225-233, https://doi.org/10.1016/j.ejmech.2013.12.061.

33. Sabouri, S.; Abaszadeh, M. Synthesis and in vitro antiproliferative effects of new dihydropyrano [3, 2-b]

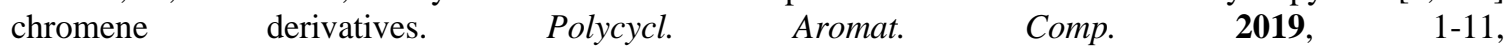
https://doi.org/10.1080/10406638.2019.1597381.

34. Maleki, E.H.; Bahrami, A.R.; Sadeghian, H.; Matin, M.M. Discovering the structure-activity relationships of different O-prenylated coumarin derivatives as effective anti-cancer agents in human cervical cancer cells. Toxicol. In Vitro 2020, 63, https://doi.org/10.1016/j.tiv.2019.104745. 
35. Mohamed, T.K.; Batran, R.Z.; Elseginy, S.A.; Ali, M.M.; Mahmoud, A.E. Synthesis, anti-cancer effect and molecular modeling of new thiazolylpyrazolyl coumarin derivatives targeting VEGFR-2 kinase and inducing cell cycle arrest and apoptosis. Bioorg. Chem. 2019, 85, 253-273, https://doi.org/10.1016/j.bioorg.2018.12.040. 